\title{
Novel "endoloop and hemoclips" technique for mucosal prolapse causing efferent loop syndrome
}
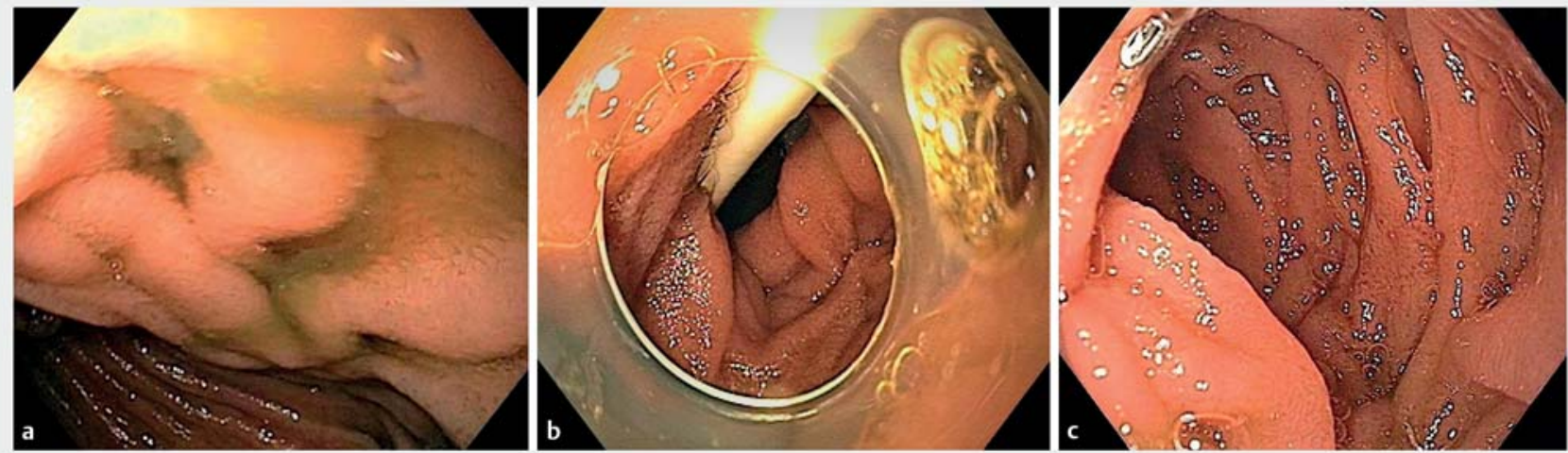

- Fig. 1 Endoscopic view. a Efferent loop syndrome secondary to mucosal fold prolapse, causing obstruction and acute angulation at entry of the efferent loop. b Opened efferent loop after endoscopic treatment, with nasojejunal tube in place. c Opened efferent loop maintained at 4-month follow-up.

Efferent loop syndrome (ELS) is defined as mechanical obstruction of the efferent jejunal limb after gastric surgery and is less common than afferent loop syndrome [1]. Adhesive band, kinking, internal herniation, intussusception, and mucosal prolapse-like stenosis are causes in the early postoperative phase, with cancer recurrence in the late phase [2]. Surgery or endoscopic treatments (metal or pigtail stents, nasojejunal tube [NJT]) are methods of relieving obstruction, depending on the cause of ELS [2-4]. We describe a novel "endoloop and hemoclips" technique that successfully resolved ELS secondary to mucosal prolapse causing obstruction.

A 32-year-old woman underwent Whipple's surgery for ampullary neuroendocrine tumor. Recovery was uneventful until postoperative day (POD) 10, with tolerance of clear liquids orally and regular bowel movements. On POD 11, she had voluminous bilious vomiting, with continuous Ryles tube aspiration (RTA) $>1 \mathrm{~L}$ / day until POD 14. Esophagogastroduodenoscopy (EGD) revealed bilious gastric residue with ELS secondary to mucosal fold prolapse, causing obstruction/angulation at entry ( Fig.1a). An NJT was placed into the efferent loop. She was un-

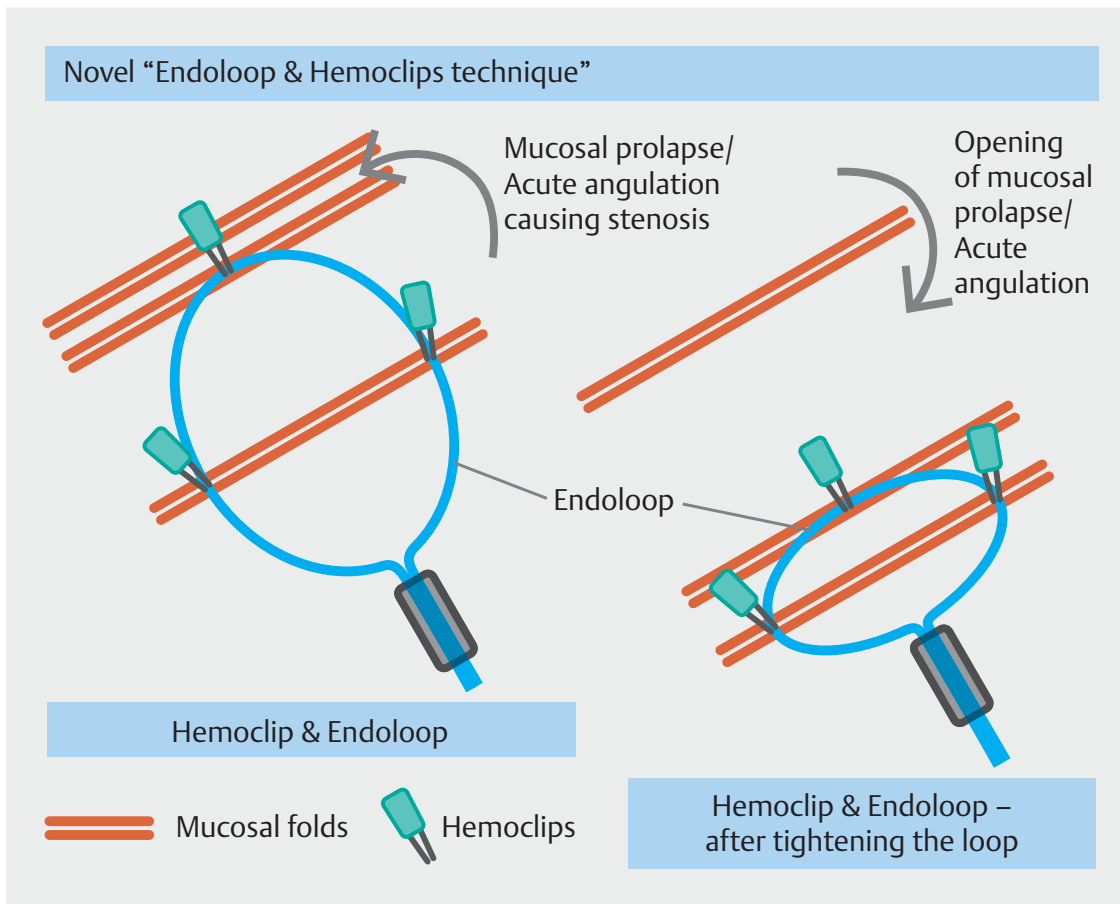

-Fig. 2 Novel "endoloop and hemoclips technique" - schematic presentation.

able to tolerate oral feeds and continued to produce large-volume RTA. The "endoloop and hemoclips” technique ( $>$ Fig. 2) involved the following steps. The endoloop with hemoclip was anchored to the mucosal fold that was prolapsing and causing ELS. Two hemoclips were applied to the loop at the opposite end, near the stopper of the endoloop, and anchored to the gastrojejunostomy wall. Finally, 


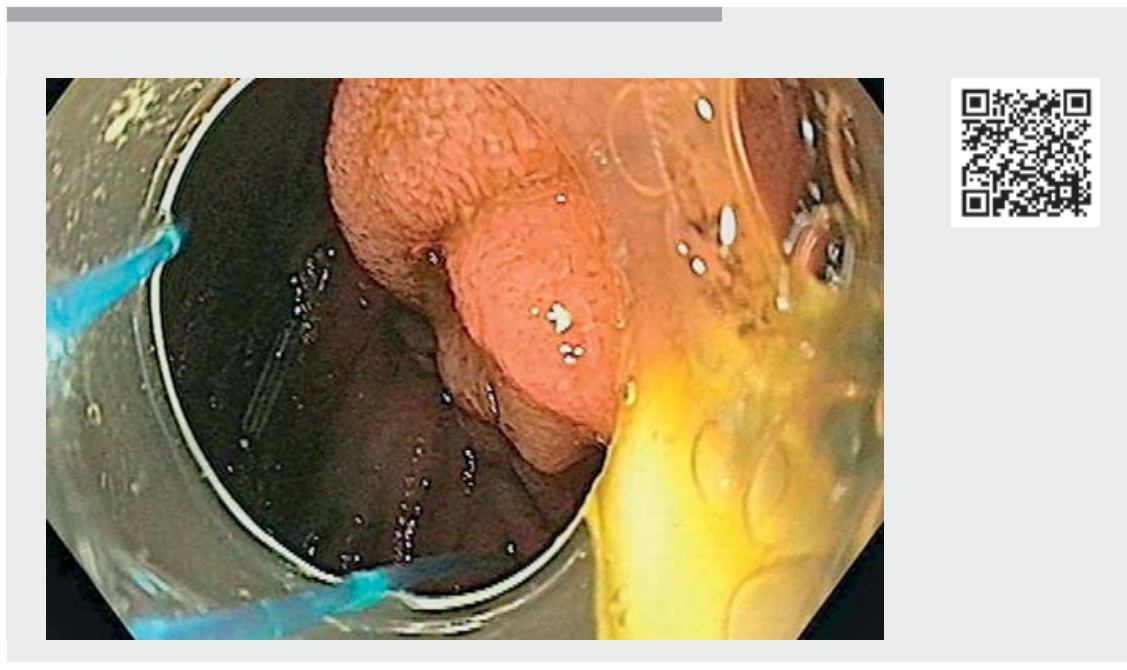

$\checkmark$ Video 1 Novel "endoloop and hemoclips" technique for relieving mucosal prolapse-like stenosis causing efferent loop syndrome.

the loop was tightened to bring the hemoclips closer together. This secured the prolapsing mucosal fold to the wall of the gastrojejunostomy, opening the efferent loop and relieving obstruction ( $\triangleright$ Fig. 1 b, $\triangleright$ Video 1 ).

EGD after 4 months revealed an open efferent loop and spontaneously detached hemoclips ( $\triangleright$ Fig. 1 c). At 7-month follow-up, she remained asymptomatic.

The technique corrects acute angulation caused by mucosal prolapse in the early postoperative phase, with durability likely, although long-term follow-up is needed.

Endoscopy_UCTN_Code_CPL_1AH_2A]

\section{Competing interests}

The authors declare that they have no conflict of interest.
[1] Jordan GL. Surgical management of postgastrectomy problems. Arch Surg 1971; 102: 251-259

[2] Tharavej C, Kattipatanapong W, Pungpapong $S$ et al. Outcome of endoscopic smallbore naso-jejunal tube stenting in early postoperative jejunal limb obstruction after gastrectomy. Surg Endosc 2019; 33: 520527

[3] Chang J, Sharma G, Boules M et al. Endoscopic stents in the management of anastomotic complications after foregut surgery: new applications and techniques. Surg Obes Relat Dis 2016; 12: 1373-1381

[4] Lee WY, Moon JS. Endoscopic treatment of efferent loop syndrome with insertion of double pigtail stent. World J Gastroenterol 2013; 19: 7209-7212

\section{Bibliography}

Endoscopy 2022; 54: E306-E307

DOI 10.1055/a-1512-8641

ISSN 0013-726X

published online 9.7.2021

(c) 2021. Thieme. All rights reserved.

Georg Thieme Verlag KG, Rüdigerstraße 14,

70469 Stuttgart, Germany

2 Department of Surgical Oncology, American Oncology Institute at Nangia Specialty Hospital, Nagpur, India

\section{Corresponding author}

\section{Manoj A. Vyawahare, MD}

Department of Medical Gastroenterology, American Oncology Institute at Nangia Specialty Hospital, MIDC Hingna, Nagpur, Maharashtra, India 440028 drmanojvyawahare@gmail.com
This section has its own submission website at https://mc.manuscriptcentral.com/e-videos 